\title{
Investigating the impact of a psychoanalytic nursing development group within an Adolescent Psychiatric Intensive Care Unit (PICU).
}

\author{
Abstract \\ Objective: To evaluate the impact of an adapted psychoanalytic work discussion \\ group for mental health nurses working in adolescent PICU \\ Background: There is no prior research investigating interventions that effectively \\ support and enable adolescent PICU nursing teams to sustain the therapeutic tasks \\ of their work and their own sense of wellbeing. \\ Methods: A bespoke psychoanalytic work discussion group was implemented within \\ an adolescent PICU. Data was collected using in-depth semi-structured interviews \\ with participants, about the impact of the group upon their practice. Data analysis \\ used thematic analysis.
}

Results: The group positively impacted upon participant knowledge and understanding, emotion management, personal efficacy, therapeutic relationship building, managing challenging behaviour, leadership, professional identity and team cohesion.

Conclusion: Mechanisms by which these outcomes were achieved are elaborated utilising the concepts of projective identification, emotional containment and 'temporary outsider-ship'. There is a need to account for the interplay between adolescent defense mechanisms, nursing anxieties and setting-specific organisational dynamics, in the design of effective support interventions for adolescent mental health nurses.

\section{Background}

The World Health Organisation (WHO, 2015) has identified the care of adolescents as a distinct specialty. Internationally, inpatient units are the most widely used element of acute adolescent mental health services (Hayes et al, 2017). Inpatient mental health environments that provide care for adolescents are unique and demanding care settings (Matthews and Williamson, 2016), which can engender significant moral distress in staff (Musto and Schreiber, 2012), contributing to burnout. The challenge for staff is related to the two-fold task of adolescent care: 
treating and managing the young person's presenting mental health disorder at the same time as supporting normal adolescent development, which has often been delayed and disrupted by those mental health difficulties (Kahila et al., 2004).

Psychiatric intensive care units (PICU) provide short-term care for people with acute and severe mental health needs, typically associated with high levels of risk of aggression to self and other (Foster, 2018). The care of service-users who present with high levels of violence is known to be complex, often provoking difficult feelings and contributing to negative work experience (Sondenaa et al., 2013). Nursing staff working in PICU have been identified as being at particularly high risk of emotional strain and burnout (Johnson, 2012).

Adolescent PICU services are at the intersection of the specialties of adolescent inpatient mental health care and PICU. Adolescent PICU environments are known to provide for a population with more diverse and complex presentations than either general adolescent psychiatric inpatient units or adult PICUs (NAPICU, 2015). Discharge pathways are more challenging and result in longer admissions (Jasti et al., 2011).

Understanding and preventing burnout in staff is important. It is associated with indifferent and hard responses towards patients, a reduction in staff mental wellbeing (Coetzee and Klopper, 2010) and has been shown to impact negatively upon the delivery of healthcare services (Sinclair et al.,2017). Yet there is no research investigating interventions that effectively support and enable mental health nursing teams working in adolescent PICU to sustain the therapeutic tasks of their work, and their own sense of wellbeing (Foster \& Smedley 2019b).

At the heart of sustaining the therapeutic task of mental health nursing is the concept Emotional Labour (Delgado et al., 2017). Emotional labour is the effort consumed by suppressing one's own emotions to care for others effectively while also caring for oneself (Edward et al, 2017). Edward et al. (2017) found that investment of emotional labour in mental health nursing is double faceted. It is a requirement for promotion of growth and satisfaction for both clients and staff, but it also contributes to staff burnout and attrition. Furthermore, that the mitigating factor between these two positions is emotional intelligence. In the context of adolescent mental health 
care provision in PICU settings, emotional intelligence must necessarily include awareness and understanding of the dynamics of emotional containment within attachment-like relationships, and a capacity to sustain 'thinking under fire'. Therefore, staff require support that permits expression of concerns in a supportive environment (Edward et al., 2017), as well as opportunities for learning and for developing psychological capacities to help them manage the specific demands of the work (Winship et al., 2019).

Work Discussion is a psychoanalytic model for delivering a specific form of reflective practice groups. Work discussion originated as a means of providing psychoanalytic perspectives for professionals for whom psychoanalysis is not their primary training (Rustin, 2008a). Psychoanalytic work discussion groups (PWDG) span the boundary of staff support and staff development. The focus is exclusively upon the emotional dynamics of the experience of work. As such, they provide a mechanism for support, whilst also working as a pedagogical approach to promote understanding of one's own emotional processes and the emotional processes of others (Winship, 2019; Dalter et al. 2018).

PWDG are externally facilitated by someone with psychoanalytic training and psychoanalytic praxis is the primary model of engaging the group in shared thinking (Jackson, 2006). This includes setting an emotionally containing structure/frame around the group in order to hold strong and potentially distressing emotions, the application of psychanalytic theory to make sense of and work through clinical experiences, and the use of facilitator observations and interpretations regarding conscious and latent communications and group processes that hold important clues for understanding the care needs of the young people. Participants are invited to think about their work role and undertake a detailed reflection upon their experience, with an expectation that learning from this process can be applied back to work. Central to this process, group members are required to provide a detailed account or observation of their work for discussion, as part of the aim of PWDGs is to support participants to increase the range of what they notice in patient interactions (Rustin, 2008a). The focus of discussion is therefore generated by the preoccupation of attendees rather than pre-selected. 
There are several arguments for the relevance of psychoanalytically informed support and development interventions for adolescent PICU nursing staff. Mental health nursing work can be described as fundamentally psychodynamic in nature (Gallop and O'Brian, 2003). Nursing staff provide emotional containment of distress, make emotional and psychological sense of what patients are doing and restore purpose (Flynn, 1998). Central to this process is the belief that change occurs within the quality of the relationships and relational environments that nurses forge (Delaney, 2017; Peplau, 1952). Nurses in hospital settings develop a uniquely detailed sense of the people they care for based on what it 'feels like' to be in their company (Foster and Smedley, 2019a). However, this knowledge is often tacit or embodied rather than articulated through language. Psychodynamic group facilitation applies theories, language and interpersonal techniques that can help to name and make use of this unique knowledge.

Winship et al. (2019) and Ruszczynski (2012), argue that PICU and similar restrictive environments require staff to have training to understand the unconscious processes to which they are subject. This is due to the very high level of childhood adversity, abuse and boundary transgression that the population admitted to intensive care, or other secure psychiatric environments, carry with them (Ruszczynski, 2012).

Similarly, working with adolescents has been noted to be distinct from providing mental health and psychotherapeutic intervention to other groups across the life span (Waddell, 2018). High levels of emotionality, reliance upon body-based solutions to psychological conflict, and a developmental tendency towards doing rather than thinking, combine with reworking of much earlier infantile experience, in the pursuit of independence and identity formation. The result is that much of the interpersonal communication that occurs between adolescent patient and worker is via non-verbal, unconscious mechanisms (Briggs 2008; Waddell 2018). The application of psychoanalytic technique with staff groups, utilising the concepts of developmental object relations and projective identification, can help to give voice to this unspoken form of communication and support staff to develop intentional interventions and therapeutic responses to young people (Winship et al., 2019; Ruszczynski, 2012). 
Psychoanalytic work discussion groups (PWDG) have been shown to be a helpful and effective forum for education and social care staff working with distressed adolescents in non-hospital settings (Ellis and Wolfe, 2019; O'Sullivan, 2019; Briggs, 2009; Jackson, 2008). A qualitative evaluation of their impact for staff working with young people in a community setting found attendee-perceived improvements in positive management of stress, understanding of, and confidence to respond to, challenging behaviour (Warman and Jackson, 2007). Therefore, the literature suggests that PWDGs could be useful for nurses working in adolescent PICU and that they have the potential to provide a mechanism for staff development and support. However, this has not yet been tested or evaluated.

Johnston and Paley (2013) have highlighted that significant adaptations technique are required to implement psychoanalytic reflective practice groups in inpatient settings. These are needed to manage cultural differences between the disciplines of psychotherapy and mental health nursing, and to accommodate the impact of the inpatient environment. In addition, there have been calls to find ways to move beyond descriptive single case study approaches for reporting on the effects and potential benefits of PWDG (Dalter et al., 2018). This requires research methods that can be sensitive to capturing the intensely subjective nature of work discussion groups, whilst also adhering to the characteristics of evaluative research that ensure rigour and objectivity (Elfer, et al., 2018). There is little research in existence that focuses on the experience of PWGD participants (Thomas and Isobel, 2019) and no research that focuses on PWDG or other forms of reflective practice group within Adolescent PICU settings. This study seeks to address these gaps in the existing literature.

\section{Study Aims}

The study aimed to implement and evaluate an original psychoanalytic work discussion group intervention, to meet the needs of nursing staff within an adolescent PICU setting. The purpose of the study was to:

- Articulate the adaptations needed to PWDG method for the specific context of Adolescent PICU

- Evaluate the experience of group participants. 
- Investigate its impact upon them and their practice

- Understand the elements of the intervention that contributed to any reported positive experiences and outcomes.

\section{Methods}

Design

The study used a cross-sectional, qualitative non-experimental design with a purposive sample. The evaluation took place when the PWDG had been running for 6 months. It was the qualitative arm of a larger mixed methods study that included a quantitative investigation of professional quality of life within adolescent PICU (Foster, 2018), and a conceptual analysis of the nature of mental health nursing within adolescent PICU settings (Foster and Smedley, 2019a, 2019b).

\section{Setting:}

An Adolescent PICU in the North of England. This was a mixed sex service providing services for young people aged 12-18 years, from across England and Wales.

\section{Intervention}

The intervention was an adapted PWDG. It was named the Nursing Development Group (NDG) to denote its adaptation and to communicate to participants that its intention was beyond solely providing staff support. The NDG met once a week for one hour. It took place immediately after the morning nursing handover and breakfast was provided. The facilitator was an adolescent psychotherapist and experienced child and adolescent mental health nurse. It was open to all members of the nursing team (qualified and unqualified) who were not required on the ward at that time to meet the minimum clinical observation levels.

\section{Aims of the Nursing Development Group:}

1. To develop the capacities of the nursing team to utilise their observational skills and reflection upon their own emotional experiences as a means of deepening their understanding of, and their capacity to collectively manage, the complex behaviours of their patients 
2. To contribute to the prevention of staff compassion-fatigue and burnout, by providing psychological support in relation to the psychological disturbance and violence to which they are subject.

3. To enable the nursing team to articulate their discipline expertise, values and team identity

A central foundation of psychoanalytic reflective practice facilitation is the suspension of judgements of good and bad. In setting the frame for the group, the facilitator role to communicate and embody a position that all emotion and action from both parties within staff-adolescent dyads is information - what matters is to explore with an open-minded curiosity the underlying meaning and drivers. The facilitator's focus was on application of developmental and psychoanalytic theory and engagement techniques, to support shared thinking and the development of a collective understanding of the young people and the dynamics within the ward. This included the underlying function of young people's more challenging behaviours; the relationship between their presentation on the ward, their life experiences/stage and psychological formulation; reflection upon skills and interventions implemented by the team that have been successful; and the impact of the young people's difficulties upon team dynamics.

Adaptations to the PWDG model: Typically, within the PWDG model facilitators will provide verbal interpretations to help members feel their indirect needs are heard and understood. Foster and Smedley (2019b) outline how the 24-hour cycle of care, lack of freedom of movement from the clinical area, and the prolonged close proximity with disturbed young people that are associated with adolescent PICU, can leave nurses vulnerable to feelings of deprivation and neglect and to concrete identification with adolescent states of mind. This can include a sensitivity to injustice and a tendency towards 'acting-out' rather than 'thinking about' (Foster, 2009). To address these issues in direct work with adolescents, the provision of emotional containment comes from using seemingly everyday aspects of care to speak to and symbolically represent/fulfil aspects of their fundamental underlying needs that "as yet have no words" (Alvarez, 2012). In a parallel process, a number of adaptations were made to the work discussion group structure and facilitator behaviour to attend to this phenomenon in the staff: 
The timing of the group was selected to acknowledge that the nursing team are working before and after the rest of the MDT's working day. It was also the quietest point of the shift to maximise the number of staff that could attend. The provision of breakfast was intended to symbolise a responsiveness to the nursing staff's own needs for care and nourishment. In recognition that not all the nursing team were able to attend the group each week, breakfast was provided for all staff on shift, not just those who attended.

Before commencement of the group, the team expressed their worries about their needs being neglected or not understood as a pessimism about the group's sustainability and the facilitator's commitment. On this basis, an intentional facilitator response was planned for days when the group could not run due to staff difficulties attending at times of high clinical acuity or staff shortages. The facilitator would go on to the ward for the usual period of the group, using the time to provide breakfast and individual contact with each member of the team. This was intended to maintain facilitator visibility, and to symbolise care and appreciation for the adversity that the team were facing.

Usually, within PWDGs participants take turns to bring a detailed written account of an element of their practice (Rustin 2008a). In recognition of the unending demands of patient observation upon the nursing team's time, this was not required of the NDG participants. Instead, at the commencement of each group they were invited to reflect on the last week and identify pressing issues that came to mind and select an issue common between them. Members were then asked to individually speak to their experience of the issue, to develop a detailed collective narrative, highlighting commonalities and points of difference.

The cultural difference between psychotherapy and nursing, and adulthood versus adolescence, can be crudely characterised as the difference between prioritising 'thinking about' and prioritising intentional action or 'doing'. Focusing on pragmatic action-focused solutions is also a mechanism by which nursing teams defend themselves from being overwhelmed by the distress and disturbance to which they are subject. This can lead to active resistance to exploring underlying meaning and feeling (Foster, 2009). Group facilitation therefore employed a scaffolding process to try to bridge the gap between 'thinking about' and 'doing'. Towards the end of the 
group, participants were invited to think about the practical implications of their discussions for their practice back on the ward. This was intended to help participants see the value of exploring the emotional content of their work and to also provide a transitional space, in which the defences needed to return to the clinical area and complete their shift could be re-engaged. Unlike a traditional PWDG, the NDG also had an explicit aim of articulating the skills and strengths of the nursing team. This was intended to address findings from research in Adult PICU that nursing staff found it difficult to name what they "did" and "how" they "did it"? (Ward and Gwinner, 2015).

\section{Evaluation Process}

\section{Sample}

Qualitative data was collected from a sample of the entire staffing complement of qualified nurses and healthcare assistants (HCA), working in an Adolescent PICU Unit in the North of England $(n=22)$. All staff members on the unit had attended some NDG groups over the six-month period.on average individual staff attended once or twice a month.

Based on the focused nature of the study aims, specificity of sample, interviewer experience and intention to use questions that generate shadowed data (Morse, 2001), a purposive sample of 6-10 interviewees that reflected the diversity of roles within the team was identified in advance as needed to provide sufficient information power to address the research aims (Malterud et al., 2016; Morse, 2000, 2001). A total of seven members of staff (32\% of the total group participating in the intervention under investigation) consented to participate and were interviewed. The sample represented all components of the nursing team complement, in proportions that approximated the make-up of the team. There were $3 \mathrm{HCAs} ; 1$ preceptee nurse; 1 experienced staff nurse; 1 senior nurse and 1 HCA employed through the nursing bank, but who worked on the ward on a regular basis.

\section{Ethical Considerations}

The University Ethics Committee (HSCR14/19) and the Research Governance Committee of the participating healthcare organisation (non-NHS) granted ethical approval. All those who chose to participate provided informed consent. Participants were informed of their rights in respect of voluntariness, information access and that data would be stored securely and anonymously in accordance with data protection 
regulations. There was no identifying patient material included in the study. Material regarding specific clinical issues and service users discussed were anonymised, with staff and patient identifiers removed.

\section{Data Collection}

Data was collected through in-depth semi-structured interviews. Interviewers were independent of the work discussion group intervention to maintain rigour and reduce bias. However, interviewers were also experienced mental health clinicians in the field, with detailed understanding of the context and intervention being evaluated. This was intended to improve interview dialogue quality - one of the dimensions that is known to decide interview data quality and usability (Malterud et al., 2016).

The fundamental question in evaluative research is "has the intervention achieved its anticipated goals?" (Bryman, 2004). The interview schedule was therefore informed by the stated aims of implementing the Nursing Development Group.

In keeping with the requirement for semi-structured interview questions to be sequenced to support progression through to full elaboration of the subject under study (Galletta, 2013); the sequence of questions was informed by the domains outlined as significant in King's (2014) Professional Development Impact Evaluation Framework. This progresses from 'experience' to 'learning', to 'into practice' (behaviours and outcomes).

The interview schedule was structured around exploring participant perception of: 1) experience of the group (positive and negative); 2) effects of participation on their thoughts, feelings and behaviour; 3) Impact of group participation at an individual and team level; 4) Characteristics of the group that were helpful or facilitative of any perceived effect and impact; 5) Limitations/ways in which the intervention could be improved. Interviews were digitally recorded with participant consent and transcribed verbatim.

\section{Data Analysis}

Interviews were analysed using thematic analysis. A hybrid inductive/deductive coding method outlined by Fereday and Muir-Cochrane (2006) was employed utilising cross-case analysis. The choice of analytic method was underpinned by the fact that the research aim was realist and evaluative in nature, focused on answering questions about perceived effect and impact. Utilising an entirely inductive approach 
to understanding emerging phenomenon would therefore be disingenuous, as a structured approach for summarising and organising features of the data that relate to the research questions was required (King, 2004; Nowell et al., 2017). At the same time, the study was exploring a previously unexamined area, so capturing all aspects of participant experience was also important (King, 2004).

A data-driven approach was employed to initial coding, in order to understand and 'safeguard' participant perspective and insights. (Fereday and Muir-Cochrane, 2006). Prior to commencing initial coding, an a priori coding framework was created to facilitate second level analysis of initial coding, in order to answer the evaluative research question (Fereday and Muir-Cochrane, 2006). Both data-driven and a priori codes were reported.

\section{Process for establishing trustworthiness}

Whilst it is not possible to eliminate subjectivity within qualitative data analysis methods, adhering to principles of being systematic, transparent and reflexive can ensure rigour within the process (Elfer et al., 2018). To this end a research plan outlining all data sources was constructed. The facilitator of the NDG was not involved in the interviewing process. An archive of all data and full descriptions of the approach to analysis was created. A record of personal reflections and notes was kept through the coding and data analysis process.

The process and steps for establishing trustworthiness as outlined by Nowell et al. (2017) were followed. The researcher familiarised themselves with the whole data set, by reading all transcripts documenting theoretical and reflective themes and thoughts about themes. An a priori coding framework (Table 1) was developed and tested against case (interviewee) one. Initial coding was undertaken on a case-bycase basis. This was followed by cross-case analysis (to identify transferability of codes), with a clearly documented process for audit purposes (dependability). Themes were identified and detailed process notes re: relationship between concepts and themes were kept. Themes were then reviewed by test for referential adequacy (credibility), i.e. that they were clearly aligned to the raw interview data. Initial themes were triangulated utilising findings from the quantitative and content analysis arms of the wider research study (Foster, 2018; Foster and Smedley, 2019a, 2019b), and the NDG facilitator's reflective notes on the process. Themes were then defined and named, and a peer internal verification process was 
undertaken (Confirmability). Findings are reported in line with the COREQ checklist for reporting qualitative research (Tong et al., 2007).

\section{Table 1: A priori coding framework}

\begin{tabular}{|l|l|l|}
\hline Code 1 & Label & Group Characteristics \\
\hline & Definition & Elements of group identified as helpful/unhelpful \\
\hline Description & Process, content and structural issues \\
\hline & Label & Experience of group \\
\hline Definition & $\begin{array}{l}\text { Subjective evaluation of individual experience of participating in } \\
\text { the group }\end{array}$ \\
\hline Code 3 & Lescription & $\begin{array}{l}\text { Account of being in the group, the nature of the group and } \\
\text { thoughts and feelings about the group (good and bad) }\end{array}$ \\
\hline & Definition & $\begin{array}{l}\text { Effect of group } \\
\text { the group have affected the individuals and the wider team }\end{array}$ \\
\hline Code 4 & Description & Includes learning, awareness, understanding and behaviours \\
\hline & Label & Impact of group \\
\hline Code 5 & Definition & $\begin{array}{l}\text { The ways in which data under 'effect of group' is understood by } \\
\text { participants to have impacted on how they think, feel, behave in } \\
\text { relation to their work role }\end{array}$ \\
\hline & Label & Individual and group \\
\hline & Definition & Limitations \\
Constraints, drawbacks, understanding of negative elements \\
\hline Code 6 & Lescription & $\begin{array}{l}\text { Includes barriers, challenges, problems and suggested } \\
\text { solutions/improvements }\end{array}$ \\
\hline & Label & Other \\
\hline & Definition & $\begin{array}{l}\text { Any emergent codes from the transcriptions, not covered by the a } \\
\text { priori codes }\end{array}$ \\
\hline
\end{tabular}

\section{Findings}

Elfer et al. (2018) assert that for PWDGs to become established evidence-based interventions, analysis of potential causal relationships between intervention and outcomes is needed. In line with this, findings are organised by outcome focussed impact statements, followed by explanatory pathways or mechanisms of impact and then limitations or areas for improvement. Figure 1. provides a schematic map to illustrate the iterative relationship between the different themes and the elements of the group structure, process and content that underpin them.

\section{Impact}

Eight domains of impact were identified: 1) knowledge and understanding; 2)

Emotion management; 3) Personal efficacy; 4) Approach to challenging behaviours;

5) Therapeutic relationship with the young people; 6) Leadership; 7) Professional identity; 8) Team functioning. Table 2. provides a detailed outline of these domains. 
Figure 1. Schematic map of relationship between outcomes and elements of the group process that led to the outcomes

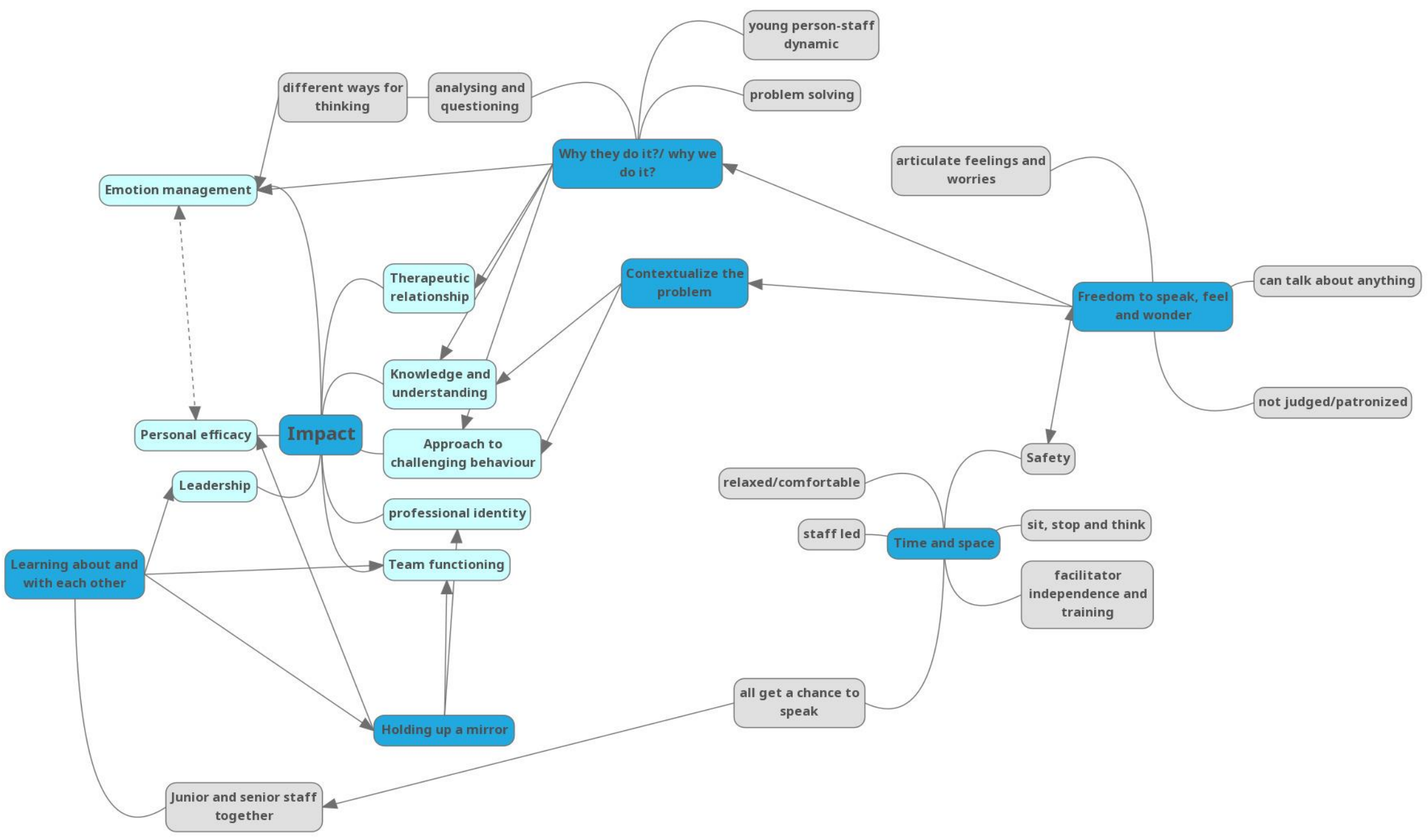


Table 2: Impact of the nursing development group

\begin{tabular}{|c|c|c|c|c|c|c|c|}
\hline $\begin{array}{l}\text { Knowledge and } \\
\text { understanding }\end{array}$ & $\begin{array}{l}\text { Emotion } \\
\text { management }\end{array}$ & $\begin{array}{l}\text { Personal } \\
\text { efficacy }\end{array}$ & $\begin{array}{l}\text { Therapeutic } \\
\text { relationships }\end{array}$ & $\begin{array}{l}\text { Challenging } \\
\text { behaviour } \\
\text { management } \\
\end{array}$ & Leadership & $\begin{array}{l}\text { Professional } \\
\text { identity }\end{array}$ & $\begin{array}{l}\text { Team } \\
\text { functioning }\end{array}$ \\
\hline $\begin{array}{l}\text { Improved } \\
\text { knowledge and } \\
\text { understanding of } \\
\text { individual young } \\
\text { people }\end{array}$ & $\begin{array}{l}\text { Can identify } \\
\text { and name } \\
\text { sources of } \\
\text { frustration } x 2\end{array}$ & $\begin{array}{l}\text { Feel more } \\
\text { prepared for } \\
\text { working with } \\
\text { patients }\end{array}$ & $\begin{array}{l}\text { Developed a } \\
\text { service-user } \\
\text { perspective } \\
\text { (empathy) x3 }\end{array}$ & $\begin{array}{l}\text { Think about my } \\
\text { impact on the } \\
\text { young people and } \\
\text { alter approach } x 2\end{array}$ & $\begin{array}{l}\text { Helped me talk } \\
\text { more confidently } \\
\text { with HCAs }\end{array}$ & $\begin{array}{l}\text { Makes us } \\
\text { realize the } \\
\text { importance and } \\
\text { value of our job } \\
\text { x4 }\end{array}$ & $\begin{array}{l}\text { Improved team } \\
\text { cohesion } x 4\end{array}$ \\
\hline $\begin{array}{l}\text { Helped me work } \\
\text { with specific } \\
\text { problems/conditions } \\
\text { (e.g. trauma and } \\
\text { dissociative } \\
\text { symptoms) x2 }\end{array}$ & $\begin{array}{l}\text { Less tendency } \\
\text { to enact } \\
\text { frustrations } \\
\text { towards the } \\
\text { young people }\end{array}$ & $\begin{array}{l}\text { More } \\
\text { understanding } \\
\text { of how to deal } \\
\text { with young } \\
\text { people on a day } \\
\text { to day basis } \\
\end{array}$ & $\begin{array}{l}\text { Improved } \\
\text { communication }\end{array}$ & $\begin{array}{l}\text { Thinking about } \\
\text { why we do things } \\
\text { has made me } \\
\text { consider } \\
\text { alternative ways } \\
\text { of doing things } x 2 \\
\end{array}$ & $\begin{array}{l}\text { Helped me help } \\
\text { new staff to } \\
\text { understand } \\
\text { underlying } \\
\text { issues }\end{array}$ & $\begin{array}{l}\text { value you } \\
\text { yourself more x2 }\end{array}$ & $\begin{array}{l}\text { More shared } \\
\text { understanding } \\
\text { between team } \\
\text { members } x 4\end{array}$ \\
\hline $\begin{array}{l}\text { Increased } \\
\text { knowledge and } \\
\text { confidence of } \\
\text { working with } \\
\text { adolescence } \times 3\end{array}$ & $\begin{array}{l}\text { Perspective } \\
\text { taking. Take a } \\
\text { step back } \\
\text { when I get } \\
\text { wound up }\end{array}$ & $\begin{array}{l}\text { Helped me to } \\
\text { have } \\
\text { confidence }\end{array}$ & $\begin{array}{l}\text { Positively changed } \\
\text { my perception of } \\
\text { young people that I } \\
\text { have found difficult } \\
\text { to nurse } x 2\end{array}$ & $\begin{array}{l}\text { I say 'lets' talk' } \\
\text { instead of 'stop } \\
\text { doing that' }\end{array}$ & $\begin{array}{l}\text { Greater } \\
\text { appreciation } \\
\text { HCAs; working } \\
\text { more to } \\
\text { empower them }\end{array}$ & $\begin{array}{l}\text { helps you feel } \\
\text { like you are } \\
\text { making a } \\
\text { difference } \times 3\end{array}$ & $\begin{array}{l}\text { Team } \\
\text { approach is } \\
\text { streamlined }\end{array}$ \\
\hline $\begin{array}{l}\text { Understanding } \\
\text { dynamics between } \\
\text { young people and } \\
\text { staff }\end{array}$ & $\begin{array}{l}\text { Think about } \\
\text { 'why?' before I } \\
\text { act on my } \\
\text { feelings } x 2\end{array}$ & $\begin{array}{l}\text { I feel more } \\
\text { positive }\end{array}$ & $\begin{array}{l}\text { Improved } \\
\text { relationships with } \\
\text { young people x2 }\end{array}$ & $\begin{array}{l}\text { Try different } \\
\text { tactics, using light } \\
\text { and shade } \\
\text { - if normally I am } \\
\text { firm, I try being a } \\
\text { bit softer }\end{array}$ & $\begin{array}{l}\text { Recognition of } \\
\text { responsibility as } \\
\text { staff nurse to } \\
\text { lead by example }\end{array}$ & $\begin{array}{l}\text { Makes a } \\
\text { difference to the } \\
\text { way you feel } \\
\text { about your job } \\
\text { x2 }\end{array}$ & $\begin{array}{l}\text { Between } \\
\text { PWDG staff } \\
\text { more likely to } \\
\text { explore ideas } \\
\text { together } \\
\text { before acting } \\
\text { x2 }\end{array}$ \\
\hline $\begin{array}{l}\text { Extended practice } \\
\text { from use of nursing } \\
\text { process to manage } \\
\text { the 'here and now', } \\
\text { to incorporating } \\
\text { young people's } \\
\text { broader needs }\end{array}$ & $\begin{array}{l}\text { Used to } \\
\text { distance } \\
\text { myself from } \\
\text { emotion - now } \\
\text { I try and } \\
\text { embrace it a } \\
\text { little more }\end{array}$ & & $\begin{array}{l}\text { Engagement with } \\
\text { the young person } \\
\text { as 'belonging to } \\
\text { someone' -builds } \\
\text { trust and reduces } \\
\text { staff v patient } \\
\text { dynamic }\end{array}$ & $\begin{array}{l}\text { Staff articulate } \\
\text { their frustrations } \\
\text { and the source of } \\
\text { them, instead of } \\
\text { acting it out }\end{array}$ & & $\begin{array}{l}\text { Given me a } \\
\text { sense of pride }\end{array}$ & $\begin{array}{l}\text { Use insights } \\
\text { from the group } \\
\text { whilst on shift } \\
\text { x2 }\end{array}$ \\
\hline
\end{tabular}


Pathways to impact

Six inter-related themes were identified relating to characteristics of the group process that contribute to participant experience and outcome. The themes identified were: 1) time and space; 2) freedom to speak, feel and wonder; 3) contextualising the problem; 4) why they do it/why we do it? 5) learning about and with each other; 6) holding up a mirror: helping us see our work.

\section{1) Time and space}

This theme describes the characteristics of the group frame, structure and facilitation, that participants identified as enabling engagement. Overwhelmingly participants reported that the group provided space to stop and think. Space referred to both practical elements and the setting of a relational environment that promoted thinking and reflection.

Within the setting, clinical close observation practices meant that staff time was often organized into five- or fifteen-minute segments. An uninterrupted hour of group time was in stark contrast to everyday life on the ward. For almost all interviewees, the 7:45am timing facilitated this thinking space as the ward was quieter with less disturbance and interruption.

"you know, having time to sit down for an hour at the start of the day, because, I think it starts you off really well, it gets you thinking." (P7)

However, one participant also recognized the challenge of this timing:

"It was challenging in the fact that it was first thing in the morning. There is very little time otherwise, so it was the ideal time, it was just a challenge!" (P3)

A balance between being relaxed and productive was highlighted as important by four interviewees. Feeling welcomed and settled into the group at the beginning facilitated engagement and group productivity.

"it is quite informal which is nice, but at the same time it is quite productive" (P1) "[The group] is quite relaxed and you feel comfortable to speak about whatever is bothering you... [The Facilitator] makes you feel at home and relaxed and calm" (P5)

Several interviewees perceived that the participant-led approach to identifying the focus of discussion was an important facilitating factor. 
"The model of the group was really helpful...staff were encouraged to bring up what they wanted to talk about. And then that would lead to a wider discussion regarding a particular topic...it would lead other members of staff to give input and their opinions and from that we'd build more of an understanding of the things that were going on." (P4)

Participants liked the equal status of group members

"[The facilitator] would chair it essentially, there was no hierarchy or line manager or 'this is what goes'. It was all listening to each other, listening to what we all had to say and then talking about it." (P2)

Group and facilitator reliability were highlighted as a positive feature which contrasted with previous staff support groups that had been trialed.

“I've been here seven years and it's been up and down... sometimes we'll have loads of support and then sometimes very minimal. So, to have that on a regular consistent basis helped a lot" (P2)

"Having it on the same day every week...because I know [the facilitator] will be here and we will have breakfast...I know that if I have asked for things at the end of the group [the facilitator] will bring them next week." (P5)

Facilitation by someone external to the organisation was important as it allowed for a level of impartiality and intersubjective distance; providing a sense of safety for the staff to be able to speak frankly about their feelings and experiences.

"Because they are independent, people feel confident in speaking what they actually feel, rather than it being a manager attached to the ward" (P1)

“I think it helped, having someone you didn't really know, but felt comfortable enough to talk to." (P2)

Three participants specifically felt that facilitator dual-training as a nurse and a psychotherapist added value. This was expressed by participant 1 as they understand but see things differently.'

"[The facilitator] challenged our ways of thinking....it was welcomed - in an inpatient/nurse environment it is very easy to get stuck within the nursing model." (P3) 


\section{2) Freedom to speak, feel and wonder}

This theme reflects the ways in which the group process combined with the characteristics described in theme 1 to create a sense of safety and containment. In turn this was described by participants as enabling a level of freedom and creativity within the group's thinking processes.

Participants reported feeling free to express themselves and talk about whatever was on their mind, especially, expressing underlying feelings and receiving support to explore those feelings safely. This contrasts with large swathes of the clinical day that requires mental health nurses to suppress and actively manage difficult emotions stirred up by nurse-patient interactions (McLaren et Al., 2016).

"I think until we had the NDG there was a lot of personal feelings that staff had regarding certain patients, that were going unsaid and left underlying. I think people were of the impression that we need to keep that under wraps. [patients] stir up uncomfortable feelings or you are frustrated, it's like 'well we just need to get on with it because that's our job'. The NDG allowed staff to open up and go actually its ok to have those feelings, and more to the point, how do we address them and move forward?" (P4)

Central to this was security in the idea of not being judged, which came through the way the group was set up "like brainstorming to help each other out" (P5) and through facilitator communication of some core group conditions:

"It was never patronizing if you don't know something, you were never laughed at" (P2)

"The language of facilitator is accessible and relatable" (P5)

Having chance to ask questions, that maybe other team members were thinking about too, was highlighted as an important opportunity that was not always afforded whilst on the ward.

"It's alright if I don't know something, instead of [the ward] which is dead busy and some people don't want to ask questions, because they think other people are [too] busy." (P2) 
Some participants felt that having the chance to talk about how situations had made them feel and have the facilitator put their concerns into words, had helped to build confidence in the wider team to articulate how they felt, share struggles and manage frustrations outside of the group setting (P1, P3, P6).

The following themes of 'contextualising the problem' and 'why they do it/ why we do it' refer directly to facilitation of discussions that enabled staff to see the relationship between current states of mind and behaviours of young people, and their early experiences. This was achieved through sharing pertinent elements of the young people's biographies and providing accessible explanations and applications of the concepts of object-relations, projective identification, transference and countertransference, adolescent defence mechanisms and attachment and internal machinations associated with specific mental health conditions.

\section{3) Contextualising the problem}

All participants felt that sharing information about the biography of young people in their care was an important aspect of the group, that brought about changes in how they thought about and interacted with them.

"It helped staff get to a bit more about why certain kids were are with us, why they act the way that they act.... It is not always easy on a busy ward to try and read the notes and understand the history" (P2)

HCA staff considered that access to this kind of contextual information gave them a better understanding of the young people and of the characteristics of different types of mental health conditions, supporting them to take a more service-user focused perspective in relation to difficult to manage patients.

For qualified members of staff, it was the chance for more in-depth reflection, combined with application of theory and evidence to help understand particular behaviours.

"It has definitely helped me with looking at trauma....and with dissociation, I feel confident talking to people about [young person's] presentation and why they are presenting like that." (P1) 
"It keeps you remembering the evidence-base around things, rather than just: 'you do it because you do it"' (P7)

\section{4) Why they do it/why we do it?}

This theme highlights that participants considered the focus on the intersubjective interactions in staff-patient dyad valuable, as opposed to a solely patient-focused discussion.

Participant 6: "I think that was really positive about the group, that the focus was quite a lot on the team itself, rather than just the patients.... think it helped as well to think about how you are interacting with them, and what they might be getting back from what you are saying."

Most participants described how the group helped to enhance nursing formulation of the young people's issues, to include a focus on explanation rather than just description, identifying it as an important supportive element. This was described both in terms of having opportunity to use collective team knowledge of the young people to think about why they were behaving in particular ways, and to consider their own responses and practice as a staff group.

"It gives you opportunity to think about why a particular person might be presenting that way." (P1)

"The group has opened us up to a different way of thinking ...to analyzing our work." (P4)

"It's made me thing about things more. Think about why we do things? Thinking about other ways of doing things". (P7)

One participant observed that the team's understanding of the dynamics and behaviours associated with adolescence had also improved.

"It certainly benefitted me and other members of the team who don't have as much experience working with adolescents.... l'd go so far as to say I think the staff are more confident in managing some of the adolescent behavior." (P4)

An example of this was given in which staff were struggling with a young person experiencing a psychotic illness who persistently claimed that they were in a sexual 
relationship with a well-known film action hero. This was understood initially by staff as an intentional deception that undermined how they appraised the legitimacy of the rest of her symptomatology. In the group, exploration of the young person's current peer-relationships on the unit, the emotional and physical changes of puberty associated with the young person's developmental stage of early adolescence and their prior history of sexual trauma, enabled the team to re-formulate their understanding. The team came to hypothesise that the confabulation may have represented a means of managing emerging feelings of desire towards a male peer that appeared to be reciprocated, defending her against potential anxieties that she may be vulnerable to unwanted sexual approaches from that peer. By understanding that the confabulation rendered the young person unavailable and under the protection of an omnipotent other in her own mind, staff members were able to alter their approach in the direction of conferring safety and giving the young person opportunity to express her thoughts and feelings about her relationship with the peer.

Understanding or working through 'why' something might be happening was reported to reduce feelings of frustration or 'being stuck', as application of new understandings provided new practical strategies for managing. For example, understanding underlying fears and needs that drive young people's threats of violence helped staff to de-escalate young people by naming and responding to the underlying drivers, rather than focusing on extinguishing the behaviour.

"[The group] gets different things out of you: when we have all sat together and talked it out, we can think how we are going to manage it" (P1)

"Problem solving" (P1), "generating new ideas" (P3), "responding to threatening and aggressive behaviour" more effectively (P7), and "having tools to work on setting up therapeutic relationships" (P5), were identified as outcomes of exploring what was happening underneath.

\section{5) Learning about and with each other}

This theme describes how participants felt that having all grades of nursing team members together was an important part of how the group brought about positive changes. Nearly all participants highlighted that it was something that did not happen on the ward often. The only other place where this would occur would be handover. 
Handover's focus is reporting of information to ensure safe care, rather than discursive.

Having different grades of staff together sparked more plural conversations and gave a seldom available chance to air and understand differences.

"Because we had nurses, and HCAs and sometimes managers in there...because a nurse has a different view [of the ward], to the HCA, to the manager. So being able to talk openly about that...sometimes the managers might not have realized what we were having to deal with... I think it was just a circle where we're all learning from each other." (P2)

Hearing all perspectives of the team was identified as helping to develop shared understanding of young people's needs and the care approach. Improvement in team cohesion and a more streamlined approach to care was attributed to this function of the group.

"To be able to go through everyone's thoughts...being able to put it all together from different areas of the team. That really helped". (P6)

This concept of learning by listening to each other, extended to learning about each other. Several participants reported developing a greater appreciation of individual team members knowledge and expertise. One staff nurse described the luxury of being able to talk with, rather than directing, the HCAs that she was responsible for leading.

"Made me think about empowering HCA's, because, this isn't going to sound very nice, but I don't mean it to; sometimes when they speak I would be surprised at their level of understanding, and maybe more fool me that I didn't know that.. l'd think 'God, you are really good!” (P7)

Although participants were keen to state that the team was supportive of each other generally, a number felt that increased empathy for how others were feeling enhanced their capacities to support them, and the feeling of being supported. 


\section{6) Holding up a mirror: helping us see our work}

This theme reflects the element of the group facilitation process that participants felt improved team morale and attributed value to their work. That is being invited to notice and articulate their skills and contribution to young people's recovery, not just the challenges

For some participants, the establishment of the nursing development group itself demonstrated appreciation of the nursing team's work and need for support.

For others being encouraged to reflect on the patient journey, in order to shine a light on the elements of their work that had contributed to progress was important,

"All the day-to-day things we don't think about; the de-escalation skills and the skills we use to keep kids entertained, the language, body language, that we don't realise that we are doing. [The facilitator] gets us to reflect on them and talk about them, so that we understand what job we are actually really doing." (P5)

"We are so used to doing the practicalities of our role, taking a step back and going 'actually we are doing a good job'... it can be really hard, but if we strip it back and look, it's really complex and elaborate work that has got an enormous amount of positives." (P4)

The chance to highlight strengths was contrasted with the essential focus of ward life on mitigating risks and preventing mistakes.

"We spend so much time going we did this wrong, and this wrong, it is difficult to think about the positive things...because we've got such risky and such complex kids". (P7)

\section{Limitations of the group}

The biggest limitation highlighted by participants, was the fact that not all staff members on shift could attend, even though the time was selected to maximise the number of available staff. Participants lamented the fact that partial attendance meant not all perspectives within the team were accounted for. To mitigate, a written account of the discussion was made available for all staff to comment on between groups. 
One participant observed that when the group was needed most (high clinical acuity and frequent serious incidents) was when it was most difficult to release staff to attend.

Suggestions for maximizing attendance included, increasing the frequency of the group, running 2 shorter consecutive groups, closer monitoring to ensure attendance was distributed fairly across the whole team, gaining help from neighboring wards or managers, to cover the ward.

Whilst five participants reported that the positive impacts of group could be seen and felt in staff approaches to young people on the ward, one participant observed that the sheer volume and pace of work within the PICU setting (psychological and procedural) could limit the speed with which staff could apply learning in the moment.

\section{Discussion}

This paper makes a unique contribution to the field of adolescent mental health nursing and to psychoanalytic practice. To the author's knowledge, it is the first study to investigate the feasibility of implementing PWDGs for nurses in Adolescent PICU settings, a clinical specialty that has received little attention from research. This study has evaluated the suitability of the application of the work discussion model to an adolescent mental health inpatient PICU nursing team and its impact. The type of bespoke adaptations that can be put in place to promote sustainability and staff engagement with the intervention have been outlined. For nurses working with adolescents in restrictive inpatient settings, this study has illustrated that adaptations need to provide emotional containment through the process of 'reverie' (Bion, 1962). That is: noticing, taking in and make sense of conscious and unconscious staff communications, giving them back in a digested and digestible form, symbolised through intentional action in terms of how the group is set up. Adaptations that were used to successfully engage the staff in this study were developed by attending to the specific challenges of the adolescent PICU environment, but more importantly, to the impact of mentally distressed adolescents on staff states of mind and the attendant parallel processes.

The impact statements reported in the findings have shown that PWDG not only attended to staff wellbeing needs but also increased their capacity to deliver the 
therapeutic tasks for their work. All participants in the study reported that their experience of the NDG was positive; impacting upon their practice with young people, and their sense of professional identity. Improvements were reported in eight domains: knowledge and understanding; emotion management; personal efficacy; approach to challenging behaviours; therapeutic relationship building; leadership; professional identity; and team functioning.

Positive professional identity and a sense of value in one's work is known to protect against burnout in mental health nurses (Edward et al., 2017), which has been shown to negatively impact upon quality of healthcare delivery (Sinclair et al., 2017). The reported improvements in participant sense of personal efficacy are particularly important in adolescent PICU, where the frequency of high intensity aggression is daily (Foster, 2018). Personal efficacy is a key factor in effective management of violence and aggression and is positively correlated to staff compassion satisfaction scores and negatively correlated to secondary traumatic stress scores (Verhaeghe et al., 2016). Similarly, team cohesion is a protective factor for staff working in highaggression environments (Lauvrud et al., 2009).

The findings from the qualitive study in this paper are validated by findings of the quantitative arm of the research study, which measured professional quality of life of the nursing team during the period in which the NDG was running (Foster 2018). A sample of 17/22 nursing staff within the clinical setting reported higher compassion satisfaction and lower burnout and secondary traumatic stress scores than either mental health nurses in comparable settings, or the benchmark data for the ProQol V scale that was used in the study (Foster, 2018).

The findings, regarding the elements of the NDG that staff reported contributed to its outcomes, are discussed here in relation to projective identification of adolescent emotion, attendant psychological defenses, and the role of emotional containment for staff in creating what Briggs (2008) has termed "temporary outsider-ship". Temporary outsider-ship describes the range of ways in which adolescents, and those who care for them, need to be able to flexibly span the boundary of inside/outside in relation to the mind of self and other and family and social groups, without getting stuck on either side, in order for the essential tasks of adolescent development to be achieved. 
The organisation of young people's inpatient services along paternalistic and biomedical lines, directly challenges adolescent need for individuality and autonomy (Foster, 2009). This can activate defense mechanisms, such as acting-out, splittingoff and projecting unbearable emotions into others, to help the teenager achieve temporary relief through a state of 'mindlessness' (Waddell, 2018). In a parallel process, high work rates and focus on rapid risk mitigation cut out space for thinking and for digesting experience in staff too (Waddell 2005). Nursing staff in adolescent PICU have been shown to be particularly vulnerable to unconscious identification with the young people's unthinking states of mind and defences. Close observation requirements create geographical and temporal splits in the team, and the restrictive environment subjects them to some of the same feelings of incarceration and disempowerment (Foster and Smedley, 2019b). The themes of 'time and space' and 'learning about and with each other', in which participants talked about the importance of a space to think together, highlight the value of the NDG in creating a relationally-focused space that countered the adolescent and organisational drives towards 'just doing'.

The findings show that group and facilitator fidelity and reliability were central to creation of a relational space in which there could be sufficient candour and freedom to express the often difficult and disturbing feelings evoked by the client group. Just as direct work with adolescents needs to provide a space that is distinct from the family, but not cut off from it (Briggs, 2008), the NDG appears to have been successful because the adaptations (e.g. timing, membership, structure and process) created a space that appreciated and accommodated ward life, but did not replicate it. Participants noted elements that contrasted with the ward - relaxed, predictable, undisturbed, with no task-based demands. This included setting a tone in which all contributions were equally valid, and in which usual hierarchies within the nursing team did not apply. This concept of the horizontal exchange of ideas in groups of mixed intellectual, educational and professional levels, to increase plurality of perspective, is at the heart of the PWDG model (Rustin, 2008a).

The theme of 'Why they do it, why we do it' elaborated the role of emotional containment in providing staff support and in developing their capacities to contain and manage the feelings of the young people. Emotional containment has been described as a stepping-stone for development (Bion, 1962). Work with severely 
disturbed adolescents necessarily involves being subject to unconscious communications as young people split of and project feelings, for which they have no words or cannot bear (Foster \& Smedley, 2019a). In this context, emotional containment means that workers need to be actively receptive to feelings being projected into them, validate them and elaborate their meaning, so that this understanding is available to them and the adolescent, to inform actions or make changes (Alvarez, 2012). However, the impact of being continuously up-close to violence and trauma can also push mental health nurses to emotionally distance themselves as a survival mechanism, in order to be able to continue to function in their role (Lauvrud et al. (2009). Examples given within the findings demonstrate how the application of key psychoanalytic ideas, within a safe space in which their feeling were received, helped staff move away from concrete appraisals of behaviour and instead utilise understanding of underlying drivers to modulate their responses. Participants discussed how being in a group that is acceptant of emotion and that privileged thinking about 'why?' before rushing to an action (Winship et al, 2019), not only reduced feelings of frustration, and increased openness to emotion, but also generated intentional actions and an outcome of improved emotion management.

A further example of the importance of emotional containment is located within the theme of 'Helping us to see our work'. Being held within an acceptant, receptive gaze that confers regard for one's worth, is a central component emotionally containing relationships in early life (Winnicott, 1971). It has been argued that feeling as though one's work has no value is a greater source of pain to mental health nurses than the continuous threat of physical and psychic assault (Johnston and Paley, 2013), and directly impacts upon self-esteem in the workplace (Edward et al., 2017). Experiencing a thoughtful and curious other, who invited them to think about their contribution, was described by participants as helping them understand their work in its complexity and to sustain them in their role beyond the experience within the group. The data from participants in this theme directly parallels findings from the conceptual analysis arm of the research study in which provision of receptive and attuned nursing interactions in which young people were offered a nuanced and realistic reflection of who they are, were identified as a critical therapeutic nursing interventions (Foster \& Smedley, 2019a). 
Findings under the theme of 'freedom to speak, feel, and wonder' point to underlying persecutory anxieties within the staff group that are commonly encountered in staff working with emotionally disturbed adolescents, who themselves are often hiding fears that they are not performing their adolescent role correctly (Briggs, 2008). Participants reported that feeling safe from feelings of shame, fear of being judged, or falling short in some way, were pre-requisites to being able to explore what Rustin (2008a) called "the omnipresent, beneath-the-surface phenomena" (p5) within the group. This is in keeping with observations from educational settings, that have found PWDGs useful for working with persecutory and paranoid feelings stirred up by work (Hulusi and Maggs, 2015). In part, this can be accounted for by the psychoanalytic principle explicitly communicated in the frame of PWDG: candid expression of feelings is encouraged, because they serve a purpose. They contain important clues about young people's difficulties and needs. By noticing and naming links between young people and staff anxieties and ways of coping, one can be used to help illustrate the other.

However, the findings of this study also reveal how important the borderland position of the facilitator was in supporting the thinking process. If temporary outsider-ship is the creation of transitional space where one can use multiple perspectives and disentangle one's own feelings and the feelings of others, it is facilitated by relationships that have 'freedom of movement' within them, created by sufficient intersubjective space (Briggs, 2008). Participants described the importance of a facilitator that understood their work but saw things differently, and of being comfortable but not too familiar with them.

Spanning the border between psychotherapy and nursing 'ways of seeing', was created firstly by translating latent communications about the nurse's emotional needs into concrete communications of care (e.g. breakfast). Secondly the border was bridged through a facilitator who was both a registered mental health nurse and an adolescent psychotherapist, external to the service. This may not always be possible, or necessarily ideal - work discussion groups usually rely on interdisciplinary membership as part of the process of shining a light on each other's practice (Rustin, 2008b). However, it does highlight that successful facilitation of PWDGs for nursing teams requires facilitators to take the time to understand the 
disciplinary culture of mental health nursing, whilst also maintaining a level of separateness from it and the organisation.

\section{Study limitations and strengths}

Whilst interviews were undertaken by interviewers independent of the NDG intervention - a strength in terms of reducing bias - participants did not receive any other form of team support at the time of the study. There may have been therefore, tendency towards a collective unconscious bias of evaluating the group well, for fear of losing the only support they were getting.

This was a single centre study; therefore, results have potential to reflect the specific culture of the unit in which it was conducted. Although it had been difficult to sustain, there was a prior history in the unit of attempting to provide nursing staff support groups of some kind. The staff group may have been more accustomed to the idea of engaging in reflective group processes, which may have contributed to the group's success. Future research repeating in a range of adolescent PICU units is indicated. There is a risk of self-selection bias within the findings. The NDG group attendance was not mandatory, and all interview participants had chosen to attend. Future research, replicating this intervention in other settings, would benefit from actively seeking to recruit participants who chose not to attend the NDG, to understand the reasons for their decision.

However, overall, the sample representation is a strength of the study. The participants represented $32 \%$ of the whole nursing team within the unit. They represented all the roles within the nursing team and in proportions equivalent to distribution within the team. Although NHS England has been seeking to increase the adolescent PICU provision (NHS, 2016), at the point of data collection, the unit was one of only 5 dedicated adolescent PICUs in England. It therefore represents a significant proportion of the national workforce in this specialised field.

Another strength was the rigorous internal verification process combined with validation of the qualitative findings with two other data sources: the data from the quantitative arm of the research study and the facilitator reflective field notes, serving to validate the outcomes and themes emerging from the interviews. 


\section{Acknowledgements:}

Dr Shelly Allen and Dr Kirsty Smedley for undertaking the interviews.

Dr Shelly Allen for the internal verification process

Professor Alison Brettle for help with editing and proof reading

\section{References}

Alvarez A. (2012). The thinking heart: Three levels of psychoanalytic therapy with disturbed children. London: Routledge. https://doi.org/10.4324/9780203078358

Bion W. (1962) The Psycho-Analytic Study of Thinking. International Journal of Psychoanalysis, 43, 306-311. Accessed from Pep Web @ http://web.ebscohost.com

Briggs, S. (2008). Working with adolescents and young adults: A contemporary psychodynamic approach. Macmillan International Higher Education.

Briggs, S. (2009). Risks and opportunities in adolescence: Understanding adolescent mental health difficulties. Journal of Social Work Practice, 23(1), 49-64.

Bryman, A. (2004). Social research methods (2nd Ed.). Oxford: Oxford University Press.

Coetzee S.K., Klopper H. C. (2010). Compassion fatigue within nursing practice; a concept analysis. Nursing \& Health Sciences, 12 (2): 235-43.

Datler W., Datler M., \& Wininger M. (2018). Evaluating the impact of Work Discussion techniques on the formation of psychoanalytic skills and attitudes: research designs and first results, Infant Observation, 21:2, 204-219. https://doi.org/10.1080/13698036.2019.1566015

Delaney, K. R. (2017). Nursing in child psychiatric milieus: What nurses do: An update. Journal of Child and Adolescent Psychiatric Nursing, 30(4), 201-208.

Delgado, C., Upton, D., Ranse, K., Furness, T. and Foster, K. (2017). Nurses' resilience and the emotional labour of nursing work: an integrative review of empirical literature. International Journal of Nursing Studies, 70: 71-88.

https://doi.org/10.1016/j.ijnurstu.2017.02.008

Edward, K.-L., Hercelinskyj, G. and Giandinoto, J.A. (2017). Emotional labour in mental health nursing: an integrative systematic review. International Journal of Mental Health Nursing, 26(3): 215-225. https://doi.org/10.1111/inm.123300

Elfer, P., Greenfield, S., Robson, S., Wilson, D., \& Zachariou, A. (2018). Love, satisfaction and exhaustion in the nursery: methodological issues in evaluating the impact of Work Discussion groups in the nursery. Early Child Development and Care, 188(7), 892-904.

Ellis, G., \& Wolfe, V. (2019). Facilitating work discussion groups with staff in complex educational provisions. Open Journal of Educational Psychology, 4. 
http://www.ojep.org/ojs-2.4.2/index.php/Ojep/article/view/19 (Accessed 10 April 2020)

Fereday, J., \& Muir-Cochrane, E. (2006). Demonstrating rigor using thematic analysis: A hybrid approach of inductive and deductive coding and theme development. International Journal of Qualitative Research, 5, 80-92.

Flynn D. (1998) Psychoanalytic aspects of inpatient treatment. Journal of Child Psychotherapy, 24 (2), 283-306.

Foster C. (2009). Adolescents in Acute Mental Distress on In-patient Pediatric Settings: Some reflections from a paediatric liaison practitioner. Journal of Child \& Adolescent Psychiatric Nursing, 22(1), 16-22. http://usir.salford.ac.uk/id/eprint/31777

Foster, C. (2018). Investigating professional quality of life in nursing staff working in Adolescent Psychiatric Intensive Care Units (PICUs). The Journal of Mental Health Training, Education and Practice,14(1), 59-71.

https://doi.org/10.1108/JMHTEP-04-2018-0023

Foster C. \& Smedley K. (2019a). Understanding the nature of mental health nursing within Adolescent PICU. Part 1: identifying nursing interventions that contribute to the recovery journey of Young People. Journal of psychiatric intensive care, 15(2), 87-102. https://doi.org/10.20299/jpi.2019.012

Foster C. \& Smedley K. (2019b). Understanding the nature of mental health nursing within Adolescent PICU. Part 2: Staff experience and support needs. Journal of Psychiatric intensive care, 15(2),103-115. https://doi.org/10.20299/jpi.2019.013

Galletta, A. (2013). Mastering the semi-structured interview and beyond: From research design to analysis and publication (Vol. 18). New York: NYU press.

Gallop, R., and O'Brien, L. (2003). Re-establishing psychodynamic theory as foundational knowledge for psychiatric/mental health nursing. Issues in Mental Health Nursing, 24(2), 213-227

Hayes, C., Simmons, M., Simons, C., and Hopwood, M. (2017). Evaluating effectiveness in adolescent mental health inpatient units: a systematic review. International Journal of Mental Health Nursing, 27: 498-513.

https://doi.org/10.1111/inm. 12418

Hulusi, H. and Maggs, P. (2015). Containing the containers: work discussion group supervision for teachers - a psychodynamic approach. Educational and Child Psychology, 32(3) 30-50.

Jackson E. (2006). Developing observation skills in school settings: The importance and impact of 'work discussion groups' for staff Infant Observation. Infant Observation: International Journal of Infant Observation and Its Applications, 8(1). 517.

Jackson, E. (2008). The development of work discussion groups in educational settings. Journal of Child Psychotherapy, 34(1), pp. 62-82. 
Jasti M., Khan F., Jacob G. (2011) Journey through an adolescent PICU, three years on... European Psychiatry, 26(1), p. 303. Abstracts of the 19th European Congress of Psychiatry.

Johnston, J. and Paley, G. (2013). Mirror mirror on the ward: who is the unfairest of them all? Reflections on reflective practice groups in acute psychiatric settings, Psychoanalytic Psychotherapy, 27:2, 170-186.

https://doi.org/10.1080/02668734.2013.772535

Kahila K., Kilkku N., Kaltiala-Heino R. (2004). Psychiatric treatment and research unit for adolescent intensive care: the first adolescent forensic psychiatric service in Finland. Journal of Psychiatric and Mental Health Nursing,11, 240-244.

King, F. (2014). Evaluating the impact of teacher professional development: An evidence-based framework. Professional Development in Education, 40(1), 89-111. https://doi.org/10.1080/19415257.2013.823099

King, N. (2004). Using templates in the thematic analysis of text. In C. Cassell \& G. Symon (Eds.), Essential guide to qualitative methods in organizational research (pp. 257-270). London, UK: Sage.

Lauvrud C., Nonstad K., Palmstierna T. (2009). Occurrence of post-traumatic stress symptoms and their relationship to Professional Quality of Life (ProQol) in nursing staff at a forensic psychiatric security unit: A cross-sectional study. Health and Quality of Life Outcomes, 7, 31. https://doi.org/10.1186/1477-7525-7-31

Malterud, K., Siersma, V. D., \& Guassora, A. D. (2016). Sample size in qualitative interview studies: guided by information power. Qualitative health research, 26(13), 1753-1760.

Matthews, H., Williamson, I. (2016). Caught between compassion and control: exploring the challenges associated with inpatient adolescent mental healthcare in an independent hospital. Journal of Advanced Nursing, 72: 1042-1053. https://doi.org/10.1111/jan.12889

MacLaren, J., Stenhouse, R., \& Ritchie, D. (2016). Mental health nurses' experiences of managing work-related emotions through supervision. Journal of advanced nursing, 72(10), 2423-2434.

Morse, J. M. (2000). Determining sample size. Qualitative Health Research, 10, 3-5. Morse, J. M. (2001). Using shadowed data. Qualitative Health Research, 11, 291292.

Musto, L. and Schreiber, R. (2012). "Doing the best I can do": moral distress in adolescent mental health nursing. Issues in Mental Health Nursing, 33(3), 137-44.

National association of Psychiatric Intensive Care [NAPICU] (2015). National Minimum Standards for Psychiatric Intensive Care Units for Young People. East Kilbride: National Association of Psychiatric Intensive Care and Low Secure Units. 
Www.napicu.org.uk/wp-

content/uploads/.../CAMHS PICU NMS final Aug 2015 cx.pdf

(accessed 10 November 2017).

NHS England (2016). C11/S/d tier 4 CAMHS Psychiatric Intensive Care Unit Service Specification (DRAFT), Gateway Ref. No. 06097. London: NHS England

Publications www.engage.england.nhs.uk/consultation/camhs/user uploads/c11-sdchld-adolescent-picu-serv-spec.pdf (accessed 10 October 2017).

Nowell LS., Norris JM., White DE., Moules NJ. (2017). Thematic Analysis: Striving to Meet the Trustworthiness Criteria. International Journal of Qualitative Methods, 16, 1-13. https://doi.org/10.1177/1609406917733847

O'Sullivan W. (2019). Creating space to think and feel in child protection social work; a psychodynamic intervention. Journal of Social Work Practice, 33:1, 15-25, https://doi.org/10.1080/02650533.2018.1460589

Peplau H. E. (1952) Interpersonal relations in nursing. Putnam: New York.

Rustin M. (2008a). Work discussion: some historical and theoretical considerations. In: Rustin, M., Bradley, J. (Eds) Work Discussion: Professional Practice with Children and Families London: Karnac Books. Routledge (pp 3-21).

Rustin, M. (2008b). Work Discussion: Implications for Research and Policy. In: Rustin, M., Bradley, J. (Eds) Work Discussion: Professional Practice with Children and Families. London: Karnac Books. (pp 267-284).

Ruszczynski S. (2012). What makes a secure setting secure? in Adlam, Aiyegbusi, Kleinot, Motz and Scanlon (Editors), The Therapeutic Milieu Under Fire. Kingsley Norton.

Sinclair, S., Raffin-Bouchal, S., Venturato, L., Mijovic-Kondejewski, J. and SmithMacDonald, L. (2017). Compassion fatigue: a meta-narrative review of healthcare literature, International Journal of Nursing Studies, 69, 9-24.

Sondenaa, E., Lauvrud, C., Sandvik, M., Nonstad, K. and Whittington, R. (2013). Resilience and professional quality of life in staff working with people with intellectual disabilities and offending behaviour in community based and institutional settings, Health Psychology Research, 1(1), 11-15.

Steiner, J. (2003). Psychic retreats: Pathological organizations in psychotic, neurotic and borderline patients. London: Routledge.

Thomas M., Isobel S. (2019). 'A different kind of space': Mixed methods evaluation of facilitated reflective practice groups for nurses in an acute inpatient mental health unit. Archives of Psychiatric Nursing, 33, 154-159.

Tong, A., Sainsbury, P., \& Craig, J. (2007). Consolidated criteria for reporting qualitative research (COREQ): a 32 -item checklist for interviews and focus groups. International journal for quality in health care, 19(6), 349-357. 
Verhaeghe S., Duprez V., Beeckman D., Leys J., Van Meijel B., Van Hecke A. (2016). Mental Health Nurses' Attitudes and Perceived Self-Efficacy Toward Inpatient Aggression: A Cross-Sectional Study of Associations with Nurse-Related Characteristics. Perspectives in Psychiatric Care, 52, 12-24.

Waddell, M. (2005). Living in two worlds: Psychodynamic theory and social work practice. http://www. psychoanalysis-and-therapy.com/human nature/freeassociations/waddell\%20-\%20living in two worlds.htm (Accessed 9 April 2020).

Waddell M. (2018). On Adolescence: Inside stories. Karnac Books. Oxon: Routledge. (Chapter 9).

Warman, A., \& Jackson, E. (2007). Recruiting and retaining children and families' social workers: The potential of work discussion groups. Journal of Social Work Practice, 21(1), 35-48.

World Health Organization [WHO] (2015). Building an adolescent-competent workforce. Policy brief. World Health Organization.

https://www.who.int/maternal child adolescent/documents/adolescent-competentworkforce/en/ (Accessed 9 April 2020).

Winship G., Shaw S., and Haigh R. (2019). Group supervision for prison officers: an orthopedagogical approach to emotional management, The Journal of Forensic Psychiatry \& Psychology, 30:6, 1006-1020.

https://doi.org/10.1080/14789949.2019.1673794 